Will correspondents please note that space is limited and shorter letters have a greater chance of publication. The Editors reserve the right to cut letters and also to eliminate multitudinous references. Please try to be concise, strictly relevant and interesting to the reader.

\section{CHARACTERISTICS OF STUDENTS ATTENDING A PSYCHIATRIST}

DeAR Sir,

I would like to comment on the findings reported by O'Mahony and O'Brien (Journal, December, 1980, 137, 547-50). The authors write of 'psychiatric morbidity' and 'incidence rate'. They make no distinction between incidence (cases developing in a specified period of time) and prevalence (number of cases in a population aggregate during a stated interval). In relation to their contention that psychiatric disturbance is no commoner in the first year, it must be pointed out that their data take no account of the likelihood of unreported psychiatric disturbance, disturbance managed by physicians and not referred or seen by physicians or psychiatrists outside the University Health Service and numbers of students dropping out. This last point may be important, as psychiatric disturbance (detected or otherwise) may lead to withdrawal from college (Lucas et al, 1966). It has also been noted in the U.K. that student losses are higher in the first year than subsequently (University Grants Committee, 1968).

So far as I know the earliest report relating type of psychiatric disturbance to time of first consultation, was Linken's careful analysis of the 1951 and 1952 undergraduate intakes at University College, London; in this study presentation of 'serious' disorders was heavily skewed, not only to the first year, but to the first months of the first year (data reported by Malleson, 1958). Payne (1969) noted that this pattern was confirmed by other workers. Such findings and other considerations led to endeavours by health services in higher education to make contact with students at risk psychiatrically as early as possible, and at the present time many services use screening forms which aim to identify health problems, physical or psychiatric, a procedure endorsed by the recent report of the Royal College of Physicians (1979).

The authors do not discuss the very great problems in comparing psychiatric studies where criteria of case definition, context, and methodology differ (see Payne, 1969), though they do warn us that the significant differences in their study (which one?) may be due to "selective factors . . . in the recognition of mental illness...".

The importance of criteria of categorization is clearly illustrated by Still's work at Leeds (Still, 1959, and 1966). In his first survey, which spanned a ten year period, he used a four category classification of severity of disturbance, and found overall that 14.7 per cent of 10,502 students seen (more than 90 per cent of the population at risk) presented psychological symptoms of some degree of severity. When all categories of disturbance were taken together, there was a clear sex difference (men 12 per cent, women 20 per cent). When compared by categories, however, the sex difference disappears for 'severe' cases (men 0.96 per cent and women 0.98 per cent), and begins to show when severe and moderately severe cases are taken together (men 4.7 per cent, women 5.8 per cent). The overall sex difference, in other words, depends on the over-representation in women of milder categories of disturbance. In his second study these broad findings were confirmed. In addition he noted a clear over-representation of disturbance in Arts students independent of sex distribution.

The finding of a higher proportion of Roman Catholic students in the psychiatric group is of interest. It suggests testable hypotheses; for example, a high degree of conflict between internal standards and social pressures. Crown et al (1977) noted that scores high on conscience and low on self esteem characterized a population of disturbed students.

Finally, the authors' finding of an over representation of psychiatric morbidity in medical students confirms various studies which are reviewed in detail by Murray (1978).

Psychiatric Adviser, The Health Centre,

C. J. Lucas

University College, London

Consultant Psychotherapist,

The Portman Clinic, London

\section{References}

Crown, S., Lucas, C. J., Stringer, P. \& Supramanium, S. (1977) Personality correlates of study difficulty and academic performance in university students. II. Conscience and self-esteem. The British Journal of Medical Psychology, 50, 275-81.

Lucas, C. J., KelviN, R. P. \& OJHA, A. B. (1966) Mental health and student wastage. British Journal of Psychiatry, 112, 277-84.

Malleson, N. (1958) In The Matrix of Medicine. London: Pitman. 
MURRAY, R. M. (1978) The health of doctors: a review. Journal of the Royal College of Physicians, 12, 403-15.

PAYNe, J. (1969) Research in Student Mental Health. London: Society for Research into Higher Education.

Royal College of Physicians of London (1979) Health Services in Higher Education.

Still, R. J. (1959) Preliminary report on a ten year survey on the mental health of students. Report of the Eleventh Conference of the British Student Health Association.

_ (1966) The Mental Health of Students. Leeds University Publication.

UNIVERSTTY GRANTS COMMTTEE (1968) Enquiry into Student Progress. London: Her Majesty's Stationery Office.

\section{PREMENSTRUAL SYNDROME \\ DeAR SiR,}

Anthony Clare's (Journal, January 1981, 138, 82-83)

reservations about sine wave fitting to daily recorded symptom scores to assess and diagnose 'premenstrual' tension, and his preference for a polynomial fit and $F$ test, set us to work on that comparison. We concluded that Gödel's premenstrual hypothesis might have been as follows. To use statistics in this field you require a null hypothesis, which is a formal definition of the mathematical way the symptoms must be temporally related. But, whatever axioms you choose, there will be examples which will fit your formal definitions but not fit your clinical meaning, and vice versa.

A polynomial or harmonic analysis of enough terms will completely represent any time series, but how many terms have any clinical meaning? A sine wave is a crude representation of data from a menstrual cycle, as is a straight line of much other clinical data. However, the sine wave implies a more appropriate approach to a periodic phenomenon than a polynomial function, and the equation's constants have approximately meaningful clinical significance. The struggle for a more completely objective analysis may be commendable yet questionable.

F. A. JENNER

Royal Hallamshire Hospital,

Glossop Road,

Sheffield S10 2JF

\section{INTERMITTENT PIMOZIDE IN CHRONIC SCHIZOPHRENIA}

Dear SiR,

I read Dr McCreadie and his colleagues' recent paper (Journal, December, 1980, 137, 510-517) with great interest. Although it is cost saving, intermittent antipsychotic medication ('drug holiday') may be hazardous. Dr McCreadie rightly pointed out that tardive dyskinesia can be precipitated by "drug holiday". There may also be relapse of schizophrenia, which is sometimes called dopaminergic supersensitivity psychosis (Chouinard and Jones, 1980), as well as physical complications (Kitamura, 1976) as a rebound phenomenon.

If, on the other hand, four-day-a-week medication is recommended because of pimozide's half life as long as $\mathbf{5 0}$ hours, then why not prescribe pimozide once every other day?

Department of Neuropsychiatry,

School of Medicine,

Keio Gijuku University,

Tokyo, Japan

\section{References}

Choutnard, G. \& Jones, B. D. (1980) Neurolepticinduced supersensitivity psychosis: Clinical and pharmacologic characteristics. American Journal of Psychiatry, 136, 16-21.

KrTAmURA, T. (1976) Is the 'drug holiday' harmful? Keio Journal of Medicine, 25, 131-7.

\section{MONOSYMPTOMATIC DELUSION TREATED WITH BEHAVIOURAL PSYCHOTHERAPY}

DeAR SIR,

May I comment on the paper by Beary and Cobb (Journal, January 1981, 138, 64-66).

A patient may present with the idea that he smells (when this is not objectively the case) in a variety of different psychiatric syndromes. The symptom can occur in certain sensitive personality developments as an over-valued idea which may dominate the patient's whole psychic life. It is also sometimes seen in depressive illness as a delusion-like idea secondary to the morbid affect, in attenuated schizophrenic illness (or monosymptomatic hypochondriacal psychosis) as a delusional belief, and rarely in organic psychosyndromes. We are only given cursory clinical details of one of the three patients mentioned in the above paper, so that it is difficult to be satisfied regarding the underlying diagnosis in all three. The psychopathology of delusion is all important here. One's confidence is not helped by their woolly comment "avoidance behaviour may reinforce delusional thinking, as often happens in obsessive compulsive and phobic neurosis". Delusions do not occur in obsessional neurosis. I am not arguing that their patients were not deluded, simply that the reader needs more information to be satisfied.

My main contention, however, is with the conclusion "mono-symptomatic delusion is now a treatable condition". They report that two of their three patients improved regarding everyday behaviour, but in both the "delusion" persisted albeit with "reduced 